\title{
BMJ Open Safe clinical practice for patients hospitalised in mental health wards during a suicidal crisis: qualitative study of patient experiences
}

\author{
Siv Hilde Berg (D) , ${ }^{1}$ Kristine Rørtveit (D) , ${ }^{2,3}$ Fredrik A. Walby (D) , Karina Aase (D) ${ }^{5}$
}

To cite: Berg SH, Rørtveit K, Walby FA, et al. Safe clinical practice for patients hospitalised in mental health wards during a suicidal crisis: qualitative study of patient experiences. BMJ Open 2020;10:e040088. doi:10.1136/ bmjopen-2020-040088

- Prepublication history and additional material for this paper are available online. To view these files, please visit the journal online (http://dx.doi. org/10.1136/bmjopen-2020040088).

Received 04 May 2020 Revised 15 September 2020 Accepted 16 0ctober 2020
Check for updates

(C) Author(s) (or their employer(s)) 2020. Re-use permitted under CC BY-NC. No commercial re-use. See rights and permissions. Published by BMJ.

For numbered affiliations see end of article.

Correspondence to

Dr Siv Hilde Berg;

siv.h.berg@uis.no

\section{ABSTRACT}

Aim The aim of this study was to explore suicidal patients' experiences of safe clinical practice during hospitalisation in mental health wards. The study was guided by the following research question: How do suicidal patients experience safe clinical practice during hospitalisation in mental health wards?

Design, setting and participants A qualitative design with semistructured individual interviews was applied. Eighteen patients hospitalised with suicidal behaviour in specialised mental health wards for adults at a Norwegian hospital participated in the study. Data were analysed thematically and inductively using qualitative content analysis.

Results Patients in a suicidal crisis experienced safe clinical care in mental health wards characterised by the following three themes: (1) being recognised as suicidal,

(2) receiving tailor-made treatment and (3) being protected by adaptive practice.

Conclusion This study illuminates the experiences of safe clinical practice for patients in a suicidal crisis. The patient group was multifaceted, with variable experiences of how safe clinical practice affected their subjective experience of safety and suicidal behaviour. The finding highlights the importance of embracing personalised activities in all parts of safe clinical practice and to recognise rather than efface patients' variability in patient safety efforts.

\section{BACKGROUND}

Patients in mental health wards are a population at particular risk of suicide. ${ }^{12}$ Inpatient suicide constitutes a proportionately small but clinically important fraction of suicides, and it is a major issue for patient safety in mental inpatient care. ${ }^{3}$ How to define and understand patient safety in mental inpatient care has been rarely explored. ${ }^{45}$ Patient safety in mental healthcare is commonly described in physical terms. ${ }^{5}$ However, other topics emerge when suicidal patients' experiences are considered. In a systematic review, ${ }^{6}$ we found that suicidal inpatients felt safe due to their connection with healthcare professionals (HCPs), being protected against their suicidal impulses and through having a sense
Strengths and limitations of this study

- This study used qualitative interviews to provide rich and variable in-depth data of inpatients with suicidal behaviour, which is an under-researched group.

- The study results are suitable for analytical generalisations regarding suicidal patients' perspectives on safe clinical practice.

- The patient sample provided rich variability regarding diagnoses, symptom/function level, sex, number of previous hospital admissions and compulsory/ voluntary admissions.

- The qualitative methodological approach is not suited for assessing the effects of interventions.

of control over their lives. Therapeutic alliance, ${ }^{7}$ decreased access to lethal means ${ }^{8}$ and locus of control ${ }^{910}$ also have strong associations with suicidal behaviour, indicating that the processes patients emphasise are relevant to clinical outcomes. Patient experiences are positively associated with clinical effectiveness and patient safety across a range of disease areas and settings, and understanding them will thus increase the likelihood of improving the two other domains. ${ }^{11}$

No studies have specifically explored what suicidal patients emphasise as vital for their perception of safety during inpatient care, and the literature on suicidal patients' experiences of safe clinical practice is limited. Although asking patients at high risk of suicide about suicidal ideations is not associated with increased suicidal ideation, ${ }^{12}$ knowledge of how suicidal patients experience suicide risk assessments is limited. Suicidal patients' experiences of being behind locked doors $^{13}$ and under constant observation ${ }^{14} 15$ have been sparsely documented in the literature. Although robust evidence supports restricting access to lethal means, ${ }^{8}$ no studies have explored patients' experiences of lethal means restriction in hospital wards. 
Preventing suicides in wards is a challenging task. Like most healthcare activities, safe clinical practice for patients with suicidal behaviour is complex and unpredictable, as knowledge of its underlying principles is incomplete, which often leads to a high degree of uncertainty. ${ }^{16}$ Even expert clinicians cannot predict which patients will commit suicide, ${ }^{17-19}$ and some patients do not communicate their suicidal ideations to their HCPs. ${ }^{13}{ }^{20-22}$ The aetiological heterogeneity of suicidal behaviour further complicates the creation of an all-encompassing model of best treatment practices. Consequently, each patient is understood and approached differently. ${ }^{23}$ More knowledge on the variability of safe clinical practice from suicidal patients' perspectives is needed. Thus, this article aims to explore suicidal patients' experiences of safe clinical practice during hospitalisation in mental health wards. The study was guided by the following question: How do suicidal patients experience safe clinical practice during hospitalisation in mental health wards?

\section{METHODS}

A qualitative design with a phenomenologicalhermeneutic approach ${ }^{24}$ based on semistructured individual interviews ${ }^{25}$ was applied.

\section{Setting}

The study was conducted at a university hospital in Norway that provides specialised mental health services for patients with mental illness. The hospital treats approximately 10000 patients per year. Patients were recruited from seven mental health wards for adults: one locked acute ward, one locked specialised ward for affective disorders, four open general mental health wards and one short-term open crisis ward. A national patient safety programme for suicide prevention was taking place at the hospital wards during the data collection. The national programme included a checklist to document whether a patient had been assessed for suicide risk, had received an assessment by a specialist on the first day of admittance and had received a safety plan and follow-up appointment at discharge, as well as whether the next-of-kin had been contacted. ${ }^{26}$ The hospital had developed specific forms for the documentation of risk factors and warning signs for suicide.

\section{Participants}

The study used a purposeful sampling strategy that aimed to recruit patients with serious suicidal behaviour and/or active suicide ideations and who were admitted to open or locked wards in specialised mental health settings for adults. Patients admitted with non-suicidal self-injury were not included in the study. ${ }^{23}$ The participants were recruited by their therapists at the study sites and selfidentified as 'being in a suicidal crisis'. The sample consisted of 7 men and 11 women $(n=18)$ aged 18-57 years (mean age 40 years). All but one of the participants were of Western origin. See table 1 for details regarding the participant characteristics. A sample size of 18 participants was considered an adequate size to offer sufficient information to respond to the study aim and ensure participant variability. ${ }^{27}$

\section{Ethical considerations}

A safety plan was established that outlined the procedures for the interviewer, the patient and the therapist in case participants required increased support or mental healthcare. All participants provided voluntary and informed consent to participate in the study. They were guaranteed that the information they provided would not be passed on to HCPs in the ward, and their therapist was informed that they were participating in the study for safety reasons. To participate, the patients had to have access to a therapist in specialised mental healthcare during the study. One patient needed additional support because he was worried that he would have no support system after his discharge. The interviewer obtained permission from this participant to inform his therapist about this issue. None of the patients reported increased distress or suicidal behaviour after taking part in the research study. The interviews were performed before discharge. The timing of the interviews was determined in collaboration with the participants and their therapists to ensure that the participants were sufficiently stable to engage in the interview and without acute suicidal ideation. The study protocol is provided in online supplemental file $1 .^{28}$ The participants have been given fictitious names here.

\section{Data collection}

The interviews were conducted by the first author (SHB) between September 2016 and January 2017. The interviews were semi-structured and followed an interview guide (online supplemental file 2) designed to explore safe clinical practice from different angles. The interview guide was developed in collaboration with an advisory panel and was tested in a pilot interview. The pilot interview was included in the study. The interviews focused on the patients' experiences in the context of daily practices in mental health wards. Of interest were their interactions with HCPs and experiences of safe clinical practice. A phenomenological-hermeneutic approach was applied during the interviews, ${ }^{24}$ which implied being sensitive to openness during the interviews by following up with the participants' responses to the guided questions. ${ }^{24}$ The median interview length was $70 \mathrm{~min}$. The first author (SHB) transcribed the interviews verbatim.

\section{Analysis}

The data were analysed using a phenomenologicalhermeneutic approach to content analysis, which guided a systematic move from the manifest content towards a higher level of abstraction and interpretation. ${ }^{29}{ }^{30}$ Each interview transcript was read several times by SHB to gain an overall understanding of what the participant expressed. Collaborative discussions of first impressions were conducted with all authors. The unit of analysis was 


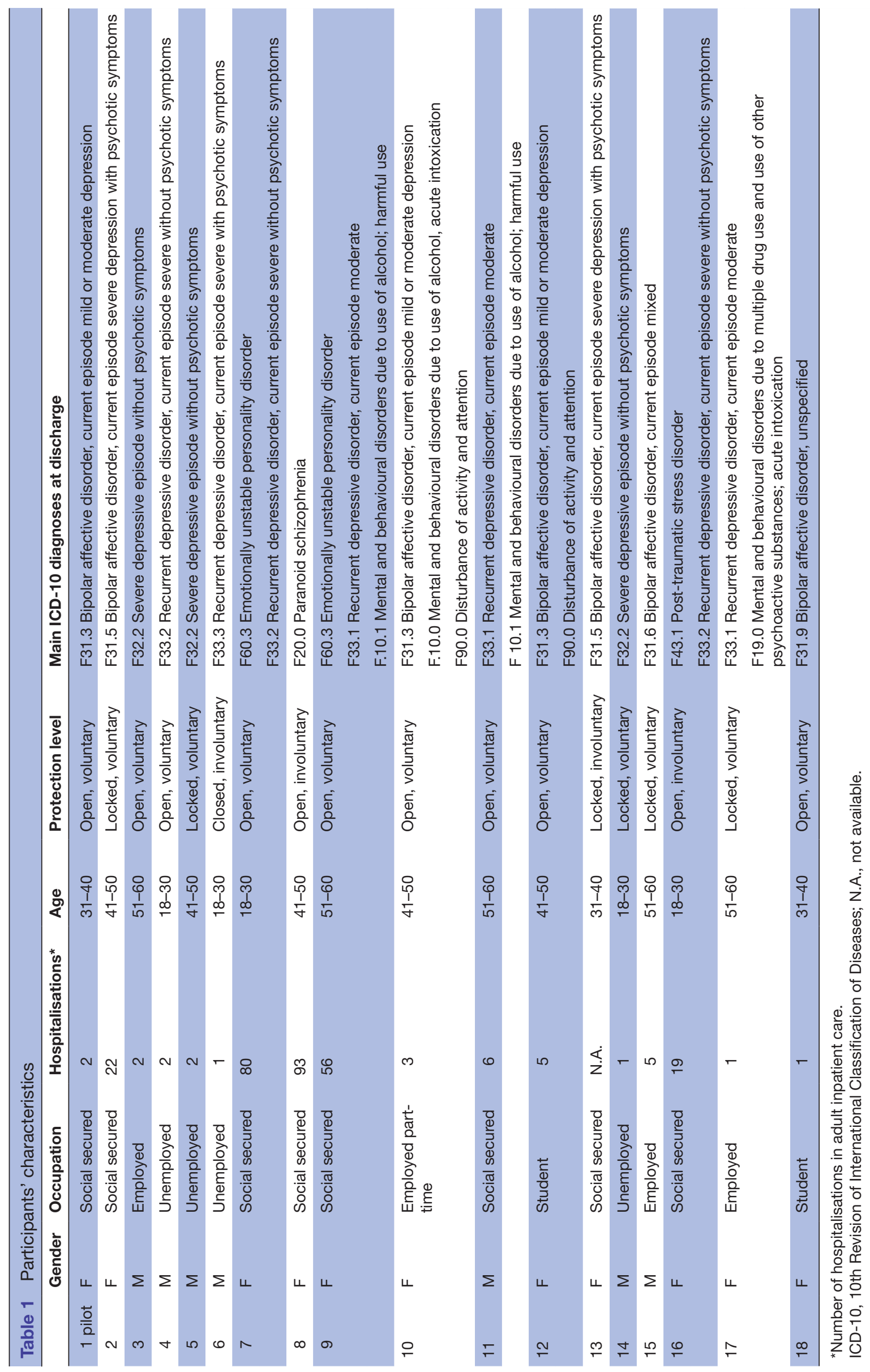


related to experiences of safe clinical practice across the entire dataset. These units were marked and condensed by SHB. In an attempt to understand the life world of each individual, the meaning units pertaining to each participant were condensed and coded separately before moving to more general codes across the dataset. ${ }^{24}$ At this stage of analysis, the manifest content was coded. ${ }^{30}$ The codes were sorted into five content areas that shed light on specific aspects (talking about suicide, recognising acute suicidality, relational interactions and therapeutic milieu, protection and treatment). Categories representing a thread through the codes were created using tables and abstracted into three themes and seven subthemes. The analytical process constantly moved between the whole and the parts. ${ }^{24}$ The authors read and reread the text to grasp the meaning in relation to the study's aim and to determine the meaning of the data for the participants. The interpretations and findings were continuously discussed by the authors, and feedback on the themes was provided by the advisory panel, which increased the study's reflexivity and allowed interpretations to be contested and nuanced. ${ }^{31}$

\section{Patient and public involvement}

Two patient experience consultants were involved in the design of the study and offered feedback on the recruitment strategy, the information material to patients, the consent form, the interview guides and early drafts of the manuscript. No patients were involved in the study recruitment. The participants were notified about the study results.

\section{RESULTS}

All participants had active suicidal ideations during their inpatient care, and nine had attempted suicide shortly before their admission to the mental health ward. Most of the patients attributed aggravations in their suicidal behaviour to deteriorations in their mental illness, unrelated to their experiences of harm during clinical practice. Safe clinical practice for suicidal inpatients was described by three themes and nine subthemes, as displayed in table 2.

\section{Being recognised as suicidal}

Patients experienced safe clinical practice when being recognised as suicidal during acute suicidal deteriorations. As they struggled to communicate their suicidal ideations, they were recognised by HCPs, who showed sensitivity to their deterioration. Their suicidal behaviours were better understood in trusted and familiar relationships.

\section{Struggle to communicate suicidal ideations}

Several participants found it difficult to verbalise their suicidal ideations, which they experienced as more profound during episodes of severe mental illness. This experience was related to losing the ability to articulate their inner thoughts when mentally ill, a fear of being locked inside a mental ward, being fixated on death or having suicidal impulses with sudden deteriorations and acting on impulse without telling anyone. They depended on others to recognise and express their psychological needs when they deteriorated. Family members fulfilled this function before admission, and HCPs did so in the ward:

I did not say so much (about my suicidal ideation) at the beginning. It was them (parents and girlfriend) who explained most of it because I did not manage to talk. I was completely broken down. (Nathan)

Because they were limited by fear, mental illness and difficulty with verbal expression, many of the participants stated that the severity of their suicidal ideations was never detected during formal risk assessments.

Many participants felt unsafe when they were hospitalised through the emergency room and the centralised acute ward because of reduced predictability in terms of whom they would meet and where they would be transferred next. For some of the participants, in particular those admitted for the first time, this insecurity prevented them from verbally communicating their suicidal ideations and reaching out to HCPs for help, as they feared being misunderstood, misinterpreted or mistreated in the form of punishment or seclusion.

\section{Sensitivity to deterioration}

Participants experienced that HCPs showed sensitivity to their acute suicidal state, which saved them from an impending suicide attempt. The HCP who responded was not always the participant's contact person. The situations were described as 'being picked up' or 'being read' by someone who was aware of their needs, who cared about them as an individual, who was vigilant and who was able to immediately make sense of changes in their mental state by reading their body language, signs of instability

Table 2 Themes and subthemes

\begin{tabular}{llll}
\hline Themes & Being recognised as suicidal & Receiving tailor-made treatment & $\begin{array}{l}\text { Being protected by adaptive } \\
\text { practice }\end{array}$ \\
\hline $\begin{array}{c}\text { Subthemes } \\
\text { Struggle to communicate suicidal } \\
\text { ideations }\end{array}$ & $\begin{array}{l}\text { Relieved emotional pressure } \\
\text { Sensitivity to deterioration }\end{array}$ & Collaborative dialogue & $\begin{array}{l}\text { Withdrawing from and mastering the } \\
\text { outside world } \\
\text { Internal and external control }\end{array}$ \\
$\begin{array}{l}\text { Understood in trusted and familiar } \\
\text { relationships }\end{array}$ & & $\begin{array}{l}\text { Closeness and distance during } \\
\text { observation }\end{array}$ \\
\hline
\end{tabular}


or signs of withdrawal. Patients experienced being seen beyond spoken words by HCPs who acted as lifeguards; they noticed and heard everything:

There is one nurse who reads me like an open book. She picked me up and managed to read me so clearly and get hold of me. Her presence prevented suicide... She says that she can see it in my face, my eyes and my body posture and that I start tightening my fists. (Aina)

The participants experienced that the HCPs immediately understood how to change their suicidal mindset through, among other strategies, talking about casual everyday topics, addressing their sleep problems, connecting with them and showing genuine interest in them, thus helping them to regulate their emotions.

Some participants also described that they required HCPs to interpret their spoken words, as they struggled to use the term 'suicidal' when communicating their suicidal ideations; for example, "I am in pain; I need to go out for a walk" (Aina) and "My life is truly hard to live" (Ester). In another example, when Patricia said, "Just send me home; there is nothing here that works for me", she planned to go home and take pills to commit suicide, but a nurse understood what she was communicating and told her that she had been neglected in the ward and that she should now be taken more seriously. Patricia expressed that this understanding stopped her from making a suicide attempt.

\section{Understood in trusted and familiar relationships}

The participants sought trusted and familiar relationships in the healthcare system because such relationships gave them predictability in terms of how their suicidal behaviour would be understood and treated. Participants who had been hospitalised previously described active strategies for being admitted to a familiar ward milieu. The safety plan helped them to be hospitalised in a familiar place. Being in a familiar place was emphasised as vital for the detection of acute deterioration because it meant that the participants would be close to HCPs who knew from experience how they deteriorated and how to intervene:

They know me, and that is why I think it is important to be admitted to the same ward. They have seen it in the change in my mental state, the things I say and do not say, my facial expressions. They have read me when I get truly, truly silent; then I am ill, and they watch me extra carefully... I have survived because they have watched me like hawks. They have given me my personal freedom, but not too much. (Gunn)

When patients did not have access to HCPs who they perceived as being able to read the fluctuations in their suicidal behaviour, their sense of trust in HCPs' response to their suicidal crises was diminished. Lack of trust caused patients to withdraw from seeking help from HCPs and to cope with their suicidal deteriorations by themselves or by being recognised by their co-patients. These strategies were unfortunate and made the participants feel unsafe. Turid described how she was saved from suicide attempts by fellow patients who detected her behaviour and called ward personnel at times when she deteriorated and by ensuring that she used medications to fall asleep in order to keep her safe from her suicidal impulses at night.

\section{Receiving tailor-made treatment}

Safe clinical practice was experienced when receiving tailor-made treatment, which relieved emotional pressure by targeting underlying stressors and mental health issues. A collaborative dialogue was preferred during suicide risk assessments.

\section{Relieved emotional pressure}

The participants presented diverse reasons for their suicidal behaviours, which were approached with equally diverse interventions. When treated as an individual, their underlying issues and stressors could be addressed, enabling them to re-establish a feeling of internal emotional control that allowed them to cope with their lives without committing suicide, at least in the short term. Experiences of safe clinical practice were highly related to whether the treatment efficiently relieved emotional pressure. For some, the emotional pressure was due to chaos in their inner worlds (eg, difficult feelings, delusions, existential issues and sleep deprivation) and/or outer worlds (eg, relational or economic issues and lack of a place to live). For Eva, her emotional pressure was relieved when she was eventually medicated with a mood stabiliser, and her delusions telling her to die faded. For Hannah, her emotional pressure was relieved when she received practical support that helped her cope economically with her new life after surviving a suicide attempt:

I was very miserable in my job. You are in a prison and they have thrown away the key. The key was the assurance that I would never go back to that job. It gave me hope to live and took away my suicidal thoughts... I felt safe when the social worker guided me in the outer world, because I knew how to take hold of my new life. (Hannah)

The patients' underlying issues were targeted by unique combinations of helpful and life-saving care at the wards that was tailored to the individual (eg, psychotherapy, medications, rest, isolation, having a strict daily structure, group therapy and activities) by diverse professionals (eg, social workers, psychologists, nurses and psychiatrists). When these issues were not addressed, the participants experienced being a great risk to themselves after discharge.

Tailor-made treatment was important to ensuring safe clinical practice for patients with complicated mental health issues, as exemplified by Janet. Janet had a history of trauma due to abuse and felt out of control of her suicidal impulses and flashbacks. She managed to find hope and to cope with her flashbacks by talking about her 
trapped emotions with a psychologist. However, during acute phases, she exhibited a severe lack of self-control, and any attempt to restrain her worsened her flashbacks and suicidality. She managed to gradually improve through treatment with sedatives during acute phases and the presence of HCPs who stayed with her in the bathroom in the dark, as this made her feel safe because no one could find her.

Feeling that the conversation relieved emotional pressure was important when talking about suicide. The participants longed for confirmation that their suffering and suicidal ideations were understandable. Many participants experienced HCPs asking them about their suicidal ideations, but their pain was not alleviated when they opened up.

They do not have the time; they are looking at their watch, as if they would rather be somewhere else. When they do not take my suicidal ideation seriously, I think I am worthless and should instead keep these thoughts to myself. (Aina)

Describing the difficult emotions and suicidal ideations involved with being in a vulnerable position, Gunn stated, "Elaborating on my suicidal thoughts is extremely personal for me. It is worse than undressing and being naked. It is like going to the gynaecologist." A lack of emotional confirmation elicited feelings of hopelessness, shame and refusal to disclose suicidal thoughts.

\section{Collaborative dialogue}

The participants had positive experiences of being assessed for suicide risk when the questions appeared to occur naturally as part of a collaborative dialogue in which they were perceived as individuals and the HCPs validated their feelings. Merely asking questions about suicidal ideations was described as 'ticking off boxes', 'being a part of a machine', and 'being interrogated', leading to the impression that their personal experiences, stories and feelings were not important:

They should ask other questions than just about suicidality, such as what your life situation is like... It is meaningless to be asked about suicidal thoughts and plans when they do not understand the context of why I do not want to live. (Kate)

The participants said that when addressing suicidal ideation, the HCPs should tailor their responses and adjust the conversation about suicide towards topics that matter instead of only giving general advice. One example of what was perceived as generic advice was reminding patients to think of their children. However, having children was not necessarily a protective factor for keeping the patients alive at different stages of their suicidal crises. The participants said that they had periods when they struggled with guilt, felt like a burden and thought that their children would manage better without them. Whether the participants experienced a need to elaborate on their suicidal ideations also varied. While some experienced fewer suicidal ideation episodes when they shared their inner suicidal thoughts and feelings, others improved by focusing on different topics (eg, finding hope through coping with economic issues and delusions).

\section{Being protected by adaptive practice}

Safe clinical practice was experienced when being protected by adaptive practice as the participants' suicidal behaviours fluctuated, and the need for protection varied between the participants. Safe clinical practice was experienced as a balance between withdrawing from and mastering the outside world, internal and external control, and closeness and distance during observation.

\section{Withdrawing from and mastering the outside world}

The participants experienced being protected from suicidal impulses during inpatient care by being removed from the overwhelming stressors and demands of the outside world that triggered their suicidal ideations. However, withdrawal was described as a short-term strategy, and they clearly stated they needed to cope with the outside world:

I struggle with guilt about not coping with things at home. When I am hospitalised, I do not get these reminders all the time, and I have fewer episodes of suicidal ideation. At home, I have so much to cope with that the suicidal thoughts are triggered. However, the experience is two-sided: I feel guilty about the fact that I am not with my family, and I feel defeated when I do not deal with my home situation because my life should not be here. (Ida)

The participants felt safe during discharge when HCPs balanced their need to withdraw from and master the outside world. They needed to feel able to cope with both their symptoms and their life situations to be ready to leave the ward. Safety was also experienced when the participants were involved in the discharge process of finding the right balance between activity and peace, testing this balance when leaving the ward and receiving support when the balance failed. The patients emphasised the need for predictability regarding follow-up after discharge for their own safety. They experienced severe anxiety about being discharged without feeling prepared. Gunn described how being discharged without being involved and feeling prepared diminished her trust in healthcare and triggered a suicide attempt:

To be notified about discharge on the same day is like hitting the pavement at $100 \mathrm{~km}$ per hour. I was discharged without being prepared, and I became very confused and even more of a danger to myself. If I am not worthy enough of getting help from mental health care, then there is nothing more to do for me; my suicidal thoughts turn active, and I have tried committing suicide. (Gunn) 


\section{Internal and external control}

The participants described experiencing safety from their suicidal impulses through internal or external control, which are related to different needs for emotional regulation and trust in HCPs and the healthcare system. Feeling safe through internal or external control changed during their suicidal crises, as described in the following statement made by Magnus:

To feel safe from myself, I needed to get out of that psychosis where I believed that I was completely bound to kill myself because I had let everything and everyone down. Because I did not truly want to kill myself... I lost my sense of self, my motor control, my sight and my concentration during the psychosis. I thought this was the way my life had become... I needed rest, isolation and medication, and with time I understood that I would get better, and then I needed to experience that I could function normally again and trust that I would not kill myself. (Magnus)

When experiencing safety through external control, the participants felt safe by being physically held back from the impulses, delusions or hallucinations commanding them to commit suicide and moments of overwhelming agitation and despair. Locked doors or restraints replaced their sense of no control, and the lack of such protection placed greater demands on their emotional regulation to maintain their self-control. The participants emphasised the importance of not having access to any potentially lethal items, such as belts or medications, in both open and closed wards to prevent suicide during episodes of deterioration. In the aftermath, they perceived that they were being saved from death when they received proper protection:

Being restrained has a calming effect on me. I can hand control over to others and relax because I know that I cannot do any harm. My suicidal thoughts fade because I know that I am totally without control... When you are so intensely agitated, nothing stops you... Being hospitalised by force has been crucial for not committing suicide. (Klaus)

When experiencing safety through internal control, participants had the freedom to experience that nothing happened as a result of their ideations, which strengthened their perceptions of being in emotional control, making them feel safe from suicide. Barred windows, locked doors and having to walk through metal detectors increased their anxiety regarding losing this freedom and provoked thoughts such as being a prisoner, a child, or having passed the point of no return.

Feeling safe or unsafe through external control was highly dependent on the patients' trust that the healthcare system would act in their best interests when they handed over some of their own power in a vulnerable situation. Patients who were admitted for the first time were sensitive to cues of trust, and locked wards could result in feelings of claustrophobia, panic attacks and more episodes of suicidal ideation. Patients' anxiety was reduced when they intuitively understood or were told that the physical barriers and procedures were intended to help them. They felt safe because they began trusting in the healthcare system. Consequently, being deprived of their personal belongings was easily accepted and intuitively understood as necessary for their own safety, because it was experienced as a necessary protection for all participants during an acute suicidal crisis.

\section{Closeness and distance during observation}

Due to the invasiveness of the observations, the participants emphasised the need to balance closeness and physical distance. They needed a balance between being acknowledged and seen and being left in peace, having their privacy respected without being given too much freedom: 'Firm but soft, but not too much freedom'.

The participants' ability to establish relational contact during constant observation varied. Their needs and their ability to connect altered as their mental state fluctuated. Some participants needed active support and dialogue with the HCPs, while others wanted to be left in peace but needed confirmation that the HCPs were present (ie, outside the room with the door open) if required. Participants experiencing a psychotic episode reported being in a mental state that left them unable to communicate and establish relationships with the HCPs. In this state, they indicated that they simply needed the HCPs to show that they genuinely cared for them, keeping them within sight and recognising their fluctuations. They described being fixated on death and constantly thinking about suicide and thus experienced the constant presence of HCPs' life-saving. Although constant observation was perceived as invasive, in the aftermath of their crises the participants perceived this practice as safe and necessary to preventing suicide:

I still hate being followed everywhere when I have a suicide plan, but they watch all the time because they care; it is a sign of humanity. They have saved me many times. (Janet)

However, observation was experienced as unsafe when the patients' need for connection and acknowledgement was neglected and they felt left on their own and ignored. It was important that the HCPs established relationships with the patients and asked them how they were doing rather than just 'checking whether they were alive' and acting as though they were 'guardians of a prison'. Such practices increased the participants' suicidality, and for some, this had a devastating effect on trust.

While under intermittent observation, patients felt safe when they had relationships with HCPs based on trust rather than control. Trusting relationships were established when the participants felt they were treated as valuable and equal human beings. Such encounters could be in the form of simple informal contact, which made the participants feel that the HCPs were available and genuinely cared about them as individuals and were not just 
doing their jobs. It made them feel safe knowing that the HCPs would intervene during a suicidal crisis if they were unable to call for help themselves.

\section{DISCUSSION}

This article aimed to explore the experiences of safe clinical practice among patients hospitalised during suicidal crises. There was rich variation in the participants' experiences of safe clinical practice expressed in the following themes: 'being recognised as suicidal', 'receiving tailormade treatment' and 'being protected by adaptive practice'.

\section{Risk detection}

'Being recognised as suicidal' highlights the experiences of patients who struggle to verbally communicate their suicidal ideations, which are more profound during severe mental illness. The connection between the severity of mental illness and the lack of verbal communication of suicidal ideations has been described among patients with depressive disorder. ${ }^{21}$ Levi-Belz $e t a \hat{l}^{2}$ found that suicide attempters who did not verbally communicate their suicidal ideations were characterised by higher levels of suicide ideation, distress and victimisation than those who did communicate their ideations. An inability to identify and communicate suicidal ideations has also been documented in a sample of patients with psychotic depression. ${ }^{13}$ The findings of the present study are also in line with other findings in the literature that shame and trust issues inhibit honest communication during suicide risk assessment. ${ }^{22}{ }^{33}$ Nevertheless, knowledge regarding how patients who do not communicate their suicidal ideations are saved by others is limited. In the present study, HCPs' awareness and engagement enabled the detection of suicidal behaviour in the participants. This study emphasises the importance of understanding warning signs among inpatients, ${ }^{34}$ particularly those who struggle to participate in a collaborative dialogue about their suicidal ideations. As warning signs vary among the participants in the present study and vary over time, the success of such an understanding seems to be dependent on HCPs who are familiar with and vigilant about changes in a patient's mental status, irrespective of whether they are that participant's contact person in the ward. These findings emphasise the importance of a high level of expertise among all HCPs who interact with patients, enabling them to connect with each patient and make sense of her/his situation.

The findings also highlight the importance of being informed about a clear pathway on admission to hospital. The importance of suicidal patients having trust in their $\mathrm{HCPs}^{35-39}$ has been well documented in the literature. Familiar and trusted relationships are important for enabling suicidal patients to feel safe because they provide predictability in how their suicidal behaviour is understood and approached. Considering that the suicide risk is highest in the first week after psychiatric hospitalisation, ${ }^{40}$ immediate admission to familiar places that patients trust may be one strategy to employ during readmissions, as highlighted in the current study.

\section{Treatment}

'Receiving tailor-made treatment' highlights the rich variation in underlying issues and associated treatment paths for patients displaying suicidal behaviours, emphasising that practice is characterised by differing treatment strategies across participants as opposed to practices with high similarity ${ }^{41}$ and that suicidal behaviour is characterised by aetiological heterogeneity. ${ }^{23}$ The findings indicated that tailor-made treatment efficiently relieved the patients' emotional pressure by addressing the individual's need to re-establish a feeling of control regarding their suicidal impulses. Individualised care and tailored services are central topics of patient experiences in healthcare ${ }^{42}$; however, their relevance to suicidal patients' experiences of safety has been less explored. The findings support the assumption that a sense of safety for the individual patient can be achieved by addressing her/his manifestations of suffering, as discussed by Undrill. ${ }^{43}$ Furthermore, for the suicidal patient, experiences of safety are related to re-establishing a feeling of control, as found by Berg et al. ${ }^{6}$

This study also addressed the processes that patients perceive as important to feel safe during suicide risk assessments. Through collaborative dialogue and by relieving emotional pressure during suicide risk assessments, harm may be avoided, and HCPs may help patients to re-establish feelings of control. The emphasis on the role of a collaborative assessment of suicide risk that accounts for the suicidal patients' individual drivers has been described elsewhere. ${ }^{44}$ Patients have stressed the importance of trust and support to verbally communicate their suicidal thoughts. ${ }^{33}{ }^{46}$ Consequently, this study supports the recommendations provided by the British National Institute for Health and Care Excellence guidelines ${ }^{47}$ to avoid using tools and scales to predict suicide; to manage risk and not merely assess it; and to identify and agree with patients regarding their specific risks. ${ }^{47}$ Experiencing safety during suicide risk assessments involves a collaborative dialogue that establishes a therapeutic alliance that includes trust, confirmation of feelings and tuning into the patient's issues to manage their emotional pressure. The findings also reflect that some patients have difficulties participating in collaborative dialogue, which is emphasised under the theme 'being recognised as suicidal'.

\section{Protection}

The theme 'being protected by adapted practice' adds knowledge regarding the dynamic, fluctuating and interactive nature of experiencing protection as a means of safe clinical practice. The experience of safe clinical practice as a balance between withdrawing from and mastering the outside world offers insights into a well-known aspect of suicide research: that suicidal risk appears to be especially 
high soon after hospitalisation. ${ }^{48}$ The study findings imply that a lack of predictability regarding discharge induces anxiety and may aggravate suicidal behaviour. This corresponds with previous research stating that suicidal patients experience anxiety when leaving a place of safety ${ }^{490}$ and require discharge preparedness to feel safe from themselves. ${ }^{6}$ The study described how a lack of discharge preparedness triggered a suicide attempt among one of the participants, highlighting its importance. This study adds to the knowledge that discharge preparedness is created in the trusted collaborative relationships between the HCPs and the patients.

The 'internal and external control' subtheme demonstrates that patients have different experiences of safety in relation to locked doors, barred windows, restraints and involuntary commitment. This finding is in accordance with other descriptions in the literature; for example, locked doors have been experienced as both 'being admitted to prison' and 'having access to shelter', ${ }^{51}$ while involuntary commitment has been experienced as both 'necessary' and 'being cared for' and as 'unjust' or a 'restriction of autonomy. ${ }^{52} 53$ This does not imply that protective interventions are entirely good or bad; it depends on what works for whom. ${ }^{54}$ It is not a matter of whether doors should be locked, but rather which patients need to be behind locked or open doors, along with when and how. Locking all wards as a means of safety may have consequences for help-seeking behaviour, compliance and recovery for patients experiencing being safe with internal control. To ensure that healthcare can adjust to a patient's need for control, it is necessary to have both open and locked wards.

Furthermore, the study indicates that some patients experience emotional regulation of their suicidal impulses through internal and external locus of control, which may interchange during the crisis. Internal locus of control strengthens the perception that one's environment, emotions and actions are under control, while external locus of control is the perception that one's behaviour is under the control of external factors. ${ }^{55}$ External locus of control has clear associations with higher levels of suicide risk $^{9} 10$ and is related to the emotional regulation of suicidal impulses in patients with borderline personality disorder ${ }^{56}$ For some patients, external locus of control may nevertheless be necessary in the acute phases of a suicidal crisis. This has also been described in a sample of psychotic and suicidal patients. ${ }^{57}$ In our study, emotional regulation was achieved through physical protection where some patients found that they could not harm themselves.

Being under physical containment means giving power to the HCPs and trusting that they will act in accordance with the patient's best interests. This is a highly vulnerable situation for the patient that depends on interpersonal trust. ${ }^{58}$ The study implies that identifying patients who suffer emotionally when they are physically protected is crucial to minimising their catastrophic thoughts and emotional reactions. Explaining the rationale of such interventions may help patients reduce their uncertainty through interpersonal trust and predictability that they are in a safe place. To our knowledge, this is the first study of patients' experiences of being deprived of lethal means in hospital wards. There is robust evidence for the preventive effect of not having access to any lethal means in hospital wards, ${ }^{8}$ and this study provides evidence that patients do not perceive this procedure as invasive when they understand its purpose.

Safe clinical practice was also a matter of maintaining a balance between closeness and distance during observation. The importance of supportive HCPs who acknowledge patients during constant observation ${ }^{15960}$ and who consider the patient's sense of control while building the therapeutic relationship ${ }^{61}$ has been described in previous research. This study adds to the importance of understanding such dynamic relationships during observation. Patients' needs change throughout a suicidal crisis, as does their capacity to connect to others. Safe clinical practice involves a flexible relationship during observations, where HCPs tune into patients' need for closeness and distance. During this complex endeavour, HCPs can make a difference between life and death. Both experiencing inattentive HCPs and feeling ignored can potentially increase suicidal behaviours and cause patients to feel unsafe. Accordingly, this study supports the perspective of Cutcliffe and Barker ${ }^{62}$ that observations should be regarded as a dynamic relational practice, without neglecting the importance of being watchful and physically present.

\section{Strengths and weaknesses of the study}

A phenomenological-hermeneutic approach was employed with a sample of 18 participants. While the methodological approach cannot study the effects of interventions, it can provide a deeper understanding of how safe clinical practice is experienced and how it varies among patients. Credibility is strengthened by including a sample that covers significant variations and participants with relevant experiences with the phenomenon under study, ${ }^{29}$ as well as through providing a sample size with sufficient information power. ${ }^{27}$ The findings of this study cannot be generalised to the entire population of patients hospitalised in mental health wards during a suicidal crisis and are not applicable to patients dying from suicide or patients who are not admitted to hospital wards during a suicidal crisis. Nevertheless, analytical generalisations can be made regarding suicidal patients' perspectives on safe clinical practice. ${ }^{63}$

\section{CONCLUSION}

This study contributes to the understanding of how suicidal patients experience safe clinical practice. Safe clinical practice is experienced by patients hospitalised during a suicidal crisis when they are recognised as suicidal, receive tailor-made treatment and are protected by adaptive practice. The patient group was multifaceted with fluctuating suicidal behaviours, which highlights the 
importance of embracing personalised activities in safe clinical practice. Safe clinical practice needs to recognise rather than efface patients' variability. This requires patient safety efforts directed toward strengthening the expert knowledge of HCPs in terms of interpersonal skills to establish trusted relationships, competence and experience with understanding and recognising deteriorations in mental illness, and how to adapt practices such as observation and suicide risk assessment to individual patients.

\section{Author affiliations}

${ }^{1}$ Division of Adult Mental Health, Stavanger University Hospital, Stavanger, Norway ${ }^{2}$ Health and Nursing Research Group, Department of Research, Stavanger University Hospital, Stavanger, Norway

${ }^{3}$ Department of Caring and Ethics, Faculty of Health Sciences, University of Stavanger, Stavanger, Norway

${ }^{4}$ National Centre for Suicide Research and Prevention, Faculty of Medicine, University of Oslo, Oslo, Norway

${ }^{5}$ Centre for Resilience in Healthcare, Faculty of Health Sciences, University of Stavanger, Stavanger, Norway

\section{Twitter Fredrik A. Walby @walby_a}

Acknowledgements We would like to thank the following advisory panel members for this study who offered feedback on the recruitment strategies, the interview guides and the manuscript draft: Dag Lieungh (patient experience consultant), Målfrid J. Frahm Jensen (patient experience consultant), Gudrun Austad (inpatient and community suicide prevention; mental health nurse), Kristin Jørstad Fredriksen (consultant psychiatrist), Liv Sand (consultant clinical psychologist) and Sigve Dagsland (consultant clinical psychologist).

Contributors All authors provided substantial contributions in the conception of the work and the analysis of the data. SHB was responsible for the design of the study, the data collection and the organisation of the data. Additionally, SHB read and coded all transcripts and developed summaries. KR and KA read half of the transcripts and drafted summaries of early impressions of the material. FW read the summaries and participated in collaborative discussions regarding first impressions of the material with all authors. All authors participated in analytical reflections and validation of the analysis. SHB drafted the manuscript, and all authors made critical revisions to the intellectual content.

Funding This study received financial support from the Western Norway Regional Health Authority, grant number 911846.

Competing interests None declared.

Patient consent for publication Not required.

Ethics approval This study was approved by the Regional Committees for Medical and Health Research Ethics (2016/34; Norway).

Provenance and peer review Not commissioned; externally peer reviewed.

Data availability statement The datasets generated and/or analysed during the present study are not publicly available due to restrictions regarding individual privacy; however, anonymised data are available from the corresponding author upon reasonable request.

Supplemental material This content has been supplied by the author(s). It has not been vetted by BMJ Publishing Group Limited (BMJ) and may not have been peer-reviewed. Any opinions or recommendations discussed are solely those of the author(s) and are not endorsed by BMJ. BMJ disclaims all liability and responsibility arising from any reliance placed on the content. Where the content includes any translated material, BMJ does not warrant the accuracy and reliability of the translations (including but not limited to local regulations, clinical guidelines, terminology, drug names and drug dosages), and is not responsible for any error and/or omissions arising from translation and adaptation or otherwise.

Open access This is an open access article distributed in accordance with the Creative Commons Attribution Non Commercial (CC BY-NC 4.0) license, which permits others to distribute, remix, adapt, build upon this work non-commercially, and license their derivative works on different terms, provided the original work is properly cited, appropriate credit is given, any changes made indicated, and the use is non-commercial. See: http://creativecommons.org/licenses/by-nc/4.0/.

\section{ORCID iDs}

Siv Hilde Berg http://orcid.org/0000-0003-0624-3727

Kristine Rørtveit http://orcid.org/0000-0002-6657-1012

Fredrik A. Walby http://orcid.org/0000-0001-5154-7397

Karina Aase http://orcid.org/0000-0002-5363-5152

\section{REFERENCES}

1 Large M, Smith G, Sharma S, et al. Systematic review and metaanalysis of the clinical factors associated with the suicide of psychiatric in-patients. Acta Psychiatr Scand 2011;124:18-19.

2 Appleby L. Suicide in psychiatric patients: risk and prevention. $\mathrm{Br} \mathrm{J}$ Psychiatry 1992;161:749-58.

3 Bowers L, Banda T, Nijman H. Suicide inside: a systematic review of inpatient suicides. J Nerv Ment Dis 2010;198:315-28.

4 Kanerva A, Lammintakanen J, Kivinen T. Patient safety in psychiatric inpatient care: a literature review. J Psychiatr Ment Health Nurs 2013;20:541-8.

5 Brickell TA, Nicholls TL, Procyshyn RM. Patient safety in mental health. Edmonton, Alberta: Canadian patient safety: Institute and Ontario Hospital Association, 2009.

6 Berg SH, Rørtveit K, Aase K. Suicidal patients' experiences regarding their safety during psychiatric in-patient care: a systematic review of qualitative studies. BMC Health Serv Res 2017;17:73.

7 Dunster-Page C, Haddock G, Wainwright L, et al. The relationship between therapeutic alliance and patient's suicidal thoughts, selfharming behaviours and suicide attempts: a systematic review. J Affect Disord 2017;223:165-74.

8 Zalsman G, Hawton K, Wasserman D, et al. Suicide prevention strategies revisited: 10-year systematic review. Lancet Psychiatry 2016;3:646-59.

9 Pearce CM, Martin G. Locus of control as an indicator of risk for suicidal behaviour among adolescents. Acta Psychiatr Scand 1993;88:409-14.

10 Evans WP, Owens P, Marsh SC. Environmental factors, locus of control, and adolescent suicide risk. CASW 2005;22:301-19.

11 Doyle C, Lennox L, Bell D. A systematic review of evidence on the links between patient experience and clinical safety and effectiveness. BMJ Open 2013;3:001570.

12 Mathias CW, Michael Furr R, Sheftall AH, et al. What's the harm in asking about suicidal ideation? Suicide Life Threat Behav 2012;42:341-51.

13 Fredriksen KJ, Schoeyen HK, Johannessen JO, et al. Psychotic depression and suicidal behavior. Psychiatry 2017;80:17-29.

14 Cardell R, Pitula CR. Suicidal inpatients' perceptions of therapeutic and nontherapeutic aspects of constant observation. Psychiatr Serv 1999;50:1066-70.

15 Pitula CR, Cardell R. Suicidal inpatients' experience of constant observation. Psychiatr Serv 1996;47:649-51.

16 Braithwaite J, Clay-Williams R, Nugus P, et al. Health care as a complex adaptive system. England: Ashgate Studies in Resilience Engineering, 2013.

17 Large M, Sharma S, Cannon E, et al. Risk factors for suicide within a year of discharge from psychiatric Hospital: a systematic metaanalysis. Aust N Z J Psychiatry 2011;45:619-28.

18 Large M, Ryan C, Nielssen O. The validity and utility of risk assessment for inpatient suicide. Australas Psychiatry 2011;19:507-12.

19 Franklin JC, Ribeiro JD, Fox KR, et al. Risk factors for suicidal thoughts and behaviors: a meta-analysis of 50 years of research. Psychol Bull 2017;143:187-232.

20 Eskin M, Schild A, Öncü B, et al. A cross-cultural investigation of suicidal disclosures and attitudes in Austrian and Turkish university students. Death Stud 2015;39:584-91.

21 Apter A, Horesh N, Gothelf D, et al. Relationship between selfdisclosure and serious suicidal behavior. Compr Psychiatry 2001;42:70-5.

22 Richards JE, Whiteside U, Ludman EJ, et al. Understanding why patients may not report suicidal ideation at a health care visit prior to a suicide attempt: a qualitative study. Psychiatr Serv 2019;70:40-5.

23 Turecki G, Brent DA. Suicide and suicidal behaviour. The Lancet 2016;387:1227-39.

24 Dahlberg K, Dahlberg H, Nystrøm M. Reflective Lifeworld research. Sweden, 2008.

25 Johnson JM, Rowlands T. The interpersonal dynamics of in-depth interviewing. In: Gubrium JF, Holstein JA, Marvasti AB, et al, eds. The 
SAGE Handbook of interview research: the complexity of the craft. Second ed. USA: SAGE, 2012.

26 Directorate of Health. The Norwegian patient safety programme: in safe hands, 2011. Available: https://www.pasientsikkerhet sprogrammet.no/om-oss/english/the-norwegian-patient-safetyprogramme-in-safe-hands

27 Malterud K, Siersma VD, Guassora AD. Sample size in qualitative interview studies: guided by information power. Qual Health Res 2016;26:1753-60.

28 Berg SH, Rørtveit K, Walby FA, et al. Safe clinical practice for patients hospitalised in a suicidal crisis: a study protocol for a qualitative case study. BMJ Open 2017;7:e012874.

29 Graneheim UH, Lindgren B-M, Lundman B. Methodological challenges in qualitative content analysis: a discussion paper. Nurse Educ Today 2017;56:29-34.

30 Graneheim UH, Lundman B. Qualitative content analysis in nursing research: concepts, procedures and measures to achieve trustworthiness. Nurse Educ Today 2004;24:105-12.

31 Malterud K. Qualitative research: Standards, challenges, and guidelines. The Lancet 2001;358:483-8.

32 Levi-Belz Y, Gavish-Marom T, Barzilay S, et al. Psychosocial factors correlated with undisclosed suicide attempts to significant others: findings from the adolescence SEYLE study. Suicide Life Threat Behav 2019;49:759-73.

33 Ganzini L, Denneson LM, Press N, et al. Trust is the basis for effective suicide risk screening and assessment in veterans. $J$ Gen Intern Med 2013;28:1215-21.

34 Rudd MD. Suicide warning signs in clinical practice. Curr Psychiatry Rep 2008:10:87-90.

35 Hagen J, Knizek BL, Hjelmeland H. Former suicidal inpatients' experiences of treatment and care in psychiatric wards in Norway. Int J Qual Stud Health Well-being 2018;13:1461514.

36 Talseth A-G, Gilje F, Norberg A. Struggling to become ready for consolation: experiences of suicidal patients. Nurs Ethics 2003;10:614-23.

37 Holm AL, Severinsson E. Struggling to recover by changing suicidal behaviour: narratives from women with borderline personality disorder. Int J Ment Health Nurs 2011;20:165-73.

38 Wiklander M, Samuelsson M, Åsberg M. Shame reactions after suicide attempt. Scand J Caring Sci 2003;17:293-300.

39 Samuelsson M, Wiklander M, Assberg M, et al. Psychiatric care as seen by the attempted suicide patient. J Adv Nurs 2000;32:635-43.

40 Qin P, Nordentoft M, Nordentoft M. Suicide risk in relation to psychiatric hospitalization: evidence based on longitudinal registers. Arch Gen Psychiatry 2005;62:427-32.

41 Hoffman RR, Militello LG. Expertice studies. In: Perspectives on cognitive task analysis: historical origins and modern communities of practice. New York: Psychology Press, 2014.

42 Wolf $\mathrm{J}$, Niederhauser V, Marshburn D, et al. Defining patient experience. Patient Exp J 2014;1:7-19.

43 Undrill G. The risks of risk assessment. Advances in Psychiatric Treatment 2007:13:291-7.

44 Jobes DA. The collaborative assessment and management of suicidality (CAMS): an evolving evidence-based clinical approach to suicidal risk. Suicide Life Threat Behav 2012;42:640-53.
45 Østlie K, Stänicke E, Haavind H. A listening perspective in psychotherapy with suicidal patients: establishing convergence in therapists and patients private theories on suicidality and cure. Psychother Res 2018;28:150-63.

46 Hom MA, Stanley IH, Podlogar MC, et al. "Are You Having Thoughts of Suicide?" Examining Experiences With Disclosing and Denying Suicidal Ideation. J Clin Psychol 2017;73:1382-92.

47 National Institute for Health \& Excellence. Self harm: longer-term management: national clinical guideline number 133. England: The British Psychological Society and The Royal College of Psychiatrists, 2012.

48 Forte A, Buscajoni A, Fiorillo A, et al. Suicidal risk following hospital discharge: a review. Harv Rev Psychiatry 2019;27:209-16.

49 Cutcliffe J, Links P, Harder $\mathrm{H}$, et al. Understanding the risks of recent discharge: the phenomenological experiences: trying to survive while living under the proverbial "Sword of Damocles". Crisis 2012b;33:265-72.

50 Cutcliffe JR, Links PS, Harder HG, et al. Understanding the risks of recent discharge: the phenomenological lived experiences- "existential angst at the prospect of discharge". Crisis 2012a;33:21-9.

51 Lindgren B-M, Ringnér A, Molin J, et al. Patients' experiences of isolation in psychiatric inpatient care: insights from a metaethnographic study. Int J Ment Health Nurs 2019;28:7-21.

52 Katsakou C, Rose D, Amos T, et al. Psychiatric patients' views on why their involuntary hospitalisation was right or wrong: a qualitative study. Soc Psychiatry Psychiatr Epidemiol 2012;47:1169-79.

53 Katsakou C, Priebe S. Patient's experiences of involuntary hospital admission and treatment: a review of qualitative studies. Epidemiol Psichiatr Soc 2007;16:172-8.

54 Roth A, Fonagy P. What works for whom?: a critical review of psychotherapy research. New York,London: Guilford Press, 2006.

55 Rotter JB. Generalized expectancies for internal versus external control of reinforcement. Psychol Monogr 1966;80:1-28.

56 Hope NH, Wakefield MA, Northey L, et al. The association between locus of control, emotion regulation and borderline personality disorder features. Personal Ment Health 2018;12:241-51.

57 Fredriksen KJ, Schaufel MA, Johannessen JO, et al. Preventing suicide among psychiatric inpatients with psychotic depression. Psychiatr Q 2019:1-14.

58 Brown P, Calnan M, Scrivener A, et al. Trust in mental health services: a neglected concept. J Ment Health 2009;18:449-58.

59 Cutcliffe JR, Stevenson C, Jackson S, et al. A modified grounded theory study of how psychiatric nurses work with suicidal people. Int J Nurs Stud 2006:43:791-802.

60 Lees D, Procter N, Fassett D. Therapeutic engagement between consumers in suicidal crisis and mental health nurses. Int J Ment Health Nurs 2014;23:306-15.

61 Vråle GB, Steen E. The dynamics between structure and flexibility in constant observation of psychiatric inpatients with suicidal ideation. J Psychiatr Ment Health Nurs 2005;12:513-8.

62 Cutcliffe JR, Barker P. Considering the care of the suicidal client and the case for 'engagement and inspiring hope' or 'observations'. J Psychiatr Ment Health Nurs 2002;9:611-21.

63 Polit DF, Beck CT. Generalization in quantitative and qualitative research: myths and strategies. Int J Nurs Stud 2010;47:1451-8. 